\title{
Photocatalytic generation of hydrogen under visible light on $\mathrm{La}_{2} \mathrm{CuO}_{4}$
}

\author{
H LAHMAR and M TRARI* \\ Laboratory of Storage and Valorization of Renewable Energies, Faculty of Chemistry (USTHB), \\ B.P. 32, 16111 Algiers, Algeria
}

MS received 22 August 2014; accepted 16 March 2015

\begin{abstract}
The semiconducting properties of $\mathrm{La}_{2} \mathrm{CuO}_{4}$ prepared by a chemical route are investigated for the first time by the photo-electrochemical technique. The optical gap is found to be $1.27 \mathrm{eV}$ and the transition is directly allowed. p-Type conductivity is demonstrated from the Mott-Schottky plot in alkaline KOH solution (0.1 M), extrapolation of the linear region to the potential axis gives a flat band potential of $-0.41 \mathrm{~V}_{\mathrm{SCE}}$, a holes density of $1.75 \times 10^{19} \mathrm{~cm}^{-3}$ and a space-charge region of $18 \mathrm{~nm}$. The electrochemical impedance spectroscopy, measured over the frequency range $\left(1 \mathrm{mHz}-10^{5} \mathrm{~Hz}\right)$, reveals the predominance of the bulk contribution with a constant phase element. The energy diagram shows the feasibility of $\mathrm{La}_{2} \mathrm{CuO}_{4}$ for the $\mathrm{H}_{2}$ evolution under visible light. The best performance occurs at $\mathrm{pH} 12.5$ in the presence of $\mathrm{S}_{2} \mathrm{O}_{3}^{2-}$ as holes scavenger. A liberation rate of $20.6 \mu \mathrm{mol} \mathrm{mn}$ (g catalyst $)^{-1}$ is obtained under full light $\left(29 \mathrm{~mW} \mathrm{~cm}^{-2}\right)$.
\end{abstract}

Keywords. $\quad \mathrm{La}_{2} \mathrm{CuO}_{4}$; optical transition; photo-electrochemical; electrochemical impedance spectroscopy; hydrogen.

\section{Introduction}

Today's energy supply has a negative impact on the environmental protection and a large part of recent research aimed at the development of semiconductor (SC) materials, a subject pertinent to the solar energy conversion ${ }^{1}$ and ecological goals. ${ }^{2}$ Indeed, fossil energy resources will soon start declining and the solar energy meets a growing demand in many fields like photovoltaic, ${ }^{3}$ thermal conversion, ${ }^{4}$ solar cells ${ }^{5}$ and photo-electrochemical (PEC) devices. ${ }^{6}$ With an average insulation of $1200 \mathrm{~W} \mathrm{~m}^{-2}$ at the Earth surface (North Africa), the solar energy is an inexhaustible energetic source. However, this energy is intermittent and must be stored during off hours and released on demand. Hence, the research is focused on the fundamental problem of short and long terms storage. ${ }^{7}$ Hydrogen is a clean fuel with a high energetic density $\left(27,000 \mathrm{cal} \mathrm{g}^{-1}\right)$, ideal for the chemical storage. Despite their chemical stability, the semiconductor oxides like $\mathrm{TiO}_{2}$, $\mathrm{SnO}_{2}$ or $\mathrm{SrTiO}_{3}$ are unattractive for PEC conversion because of their wide band gap $\left(E_{\mathrm{g}}\right)$.

The intergrowth oxides $\mathrm{AO}\left(\mathrm{ASnO}_{3}\right)_{n}$, in which $\mathrm{A}$ is an alkaline earth, belong to the perovskites family and begin to found applications in different fields like dielectric, ${ }^{8}$ PEC cells ${ }^{9}$ and humidity sensors. ${ }^{10}$ In this respect, $\mathrm{La}_{2} \mathrm{CuO}_{4}$ begin to attract interest as photocatalyst due to its ability to absorb a large part of the solar spectrum. It crystallizes in the $\mathrm{K}_{2} \mathrm{NiF}_{4}$ structure with an orthorhombic symmetry and has gained a great popularity in the 1990s because of its superconductivity with a critical temperature of $\sim 40 \mathrm{~K}$. ${ }^{11}$ This property takes its origin from oxygen insertion in the crystal lattice, resulting in mixed valences $\mathrm{Cu}^{3+/ 2+}$.

*Author for correspondence (solarchemistry@gmail.com)
$\mathrm{La}_{2} \mathrm{CuO}_{4}$ is attractive owing to its environmental friendliness characteristic, chemical stability over a wide $\mathrm{pH}$ range (4.5-14) and a band gap well suited to the solar spectrum. ${ }^{12}$ However, in contrast to physical properties, the PEC characterization of $\mathrm{La}_{2} \mathrm{CuO}_{4}$ has not been undertaken before now and little is known about the photocatalytic applications much except in recent paper of Zhang et al. ${ }^{13}$ Therefore, it seems worthwhile to extend such studies to the PEC characterization where there is still lack of information about the semiconducting properties and energy band diagram of solid/liquid junctions. The type of conductivity of $\mathrm{La}_{2} \mathrm{CuO}_{4}$ remains controversial despite many reported papers ${ }^{14,15}$ and the PEC properties bring insights on the conduction type; it may help better understanding of the interfacial mechanism at the junction $\mathrm{La}_{2} \mathrm{CuO}_{4}$ /electrolyte. An efficient photocatalyst needs a flat band potential $\left(V_{\mathrm{fb}}\right)$ as cathode as possible to have a large band bending at the interface semiconductor/electrolyte. This implies that the constituent atoms must have a small electro-affinity and this can be achieved by using elements with low ionization energy like lanthanum. The present work is focused on the PEC characterization of $\mathrm{La}_{2} \mathrm{CuO}_{4}$, synthesized by a chemical route. The potential of hydrogen evolution falls within the gap region and water is reduced spontaneously into hydrogen under visible illumination.

\section{Experimental}

$\mathrm{La}_{2} \mathrm{CuO}_{4}$ was prepared by co-precipitation because of the high hygroscopicity of $\mathrm{La}_{2} \mathrm{O}_{3}$, difficult to handle in air. Stochiometric amounts of $\mathrm{La}_{2} \mathrm{O}_{3}$ (Aldrich 97\%) pre-fired at $850^{\circ} \mathrm{C}$ and $\mathrm{Cu}\left(\mathrm{NO}_{3}\right)_{2} \cdot 6 \mathrm{H}_{2} \mathrm{O}($ Merck, $99 \%)$ were dissolved in 
$\mathrm{HNO}_{3}(9 \mathrm{~N})$; the solution was evaporated and denitrified on a hot plate; then the powder was ground in an agate mortar, heated at $900^{\circ} \mathrm{C}$ in alumina crucible and furnace cooled. The phase was identified by $\mathrm{X}$-ray diffraction using $\mathrm{Cu} \mathrm{K} \alpha$ radiation $(\lambda=0.154178 \mathrm{~nm})$. The diffuse reflectance spectrum was recorded with a UV-VIS spectrophotometer (Specord 200 plus) equipped with an integration sphere, PTFE was used as standard. The point of zero charge (pzc) was determined by measuring the equilibrium $\mathrm{pH}$ of an aqueous solution containing an excess of $\mathrm{La}_{2} \mathrm{CuO}_{4}$ powder.

For the PEC characterization, the powder was cold pressed into pellets $\left(\emptyset=13 \mathrm{~mm}\right.$, thickness $\sim 1 \mathrm{~mm}$ ) under $5 \mathrm{t} \mathrm{cm}^{-2}$ and sintered at $950^{\circ} \mathrm{C}$. The compactness averaged $80 \%$ and the mechanical properties were quite good. Silver is desirable for producing low specific contact resistance; the pellet was encapsulated in a glass holder leaving a geometrical surface area of $0.25 \mathrm{~cm}^{2}$. PEC measurements were performed in $\mathrm{KOH}(0.1 \mathrm{M})$ electrolyte under nitrogen atmosphere using a standard cell with a large Pt auxiliary electrode. The electrode potential was monitored by a PGZ 301 potentiostat (Radiometer analytical) and reported with respect to a saturated calomel electrode (SCE). $\mathrm{N}_{2}$ gas was continuously bubbled through the solution. The interfacial capacitance was measured at $10 \mathrm{~Hz}$ while the electrochemical impedance spectroscopy (EIS) was recorded over the frequency range $\left(10^{-2}-10^{5} \mathrm{~Hz}\right)$. The electrode was irradiated through a flat optical window by a tungsten lamp (200 W, Osram).

The photocatalytic tests were conducted in a closed Pyrex reactor equipped with a cooling system whose temperature was regulated at $50 \pm 1{ }^{\circ} \mathrm{C}$. Briefly, $200 \mathrm{mg}$ of $\mathrm{La}_{2} \mathrm{CuO}_{4}$ were suspended by magnetic stirring (210 rpm) in $250 \mathrm{ml}$ of alkaline solution ( $\mathrm{pH} \sim 12.5)$ containing $\mathrm{Na}_{2} \mathrm{~S}_{2} \mathrm{O}_{3}\left(10^{-3} \mathrm{M}\right)$ as reducing agent. Before each test, nitrogen stream was passed during $35 \mathrm{mn}$ in the solution with a purging rate of $10 \mathrm{ml} \mathrm{ml}^{-1}$. Visible light was produced by three tungsten lamps providing a total intensity of $29 \mathrm{~mW} \mathrm{~cm} \mathrm{~cm}^{-2}\left(2.09 \times 10^{19}\right.$ photons $)$. Hydrogen was identified by gas chromatography and the volume was collected in an inverted burette via water displacement. Blank tests were carried out and no hydrogen was observed in the dark.

\section{Results and discussion}

$\mathrm{La}_{2} \mathrm{O}_{3}$ has a great ability to react with water and $\mathrm{La}_{2} \mathrm{CuO}_{4}$ was prepared by a chemical way using nitrates as precursors. The X-ray diffraction profile is characteristic of single phase (figure 1). The pattern has noticeably narrow peaks and the oxide exhibits a good crystallinity. All peaks are indexed in an orthorhombic unit cell (SG: Fmmm) in agreement with the JCPDS card no. 38-0709. The refined lattice constants: $a=0.53339 \mathrm{~nm}, b=0.54049 \mathrm{~nm}$ and $c=1.31109 \mathrm{~nm}$ are in perfect agreement with those reported in the recent times. ${ }^{12}$ The $\mathrm{La}_{2} \mathrm{CuO}_{4}$ structure derives from one unit cell of the perovskite structure with copper at the centre combined with two perovskite unit cells with lanthanum at the

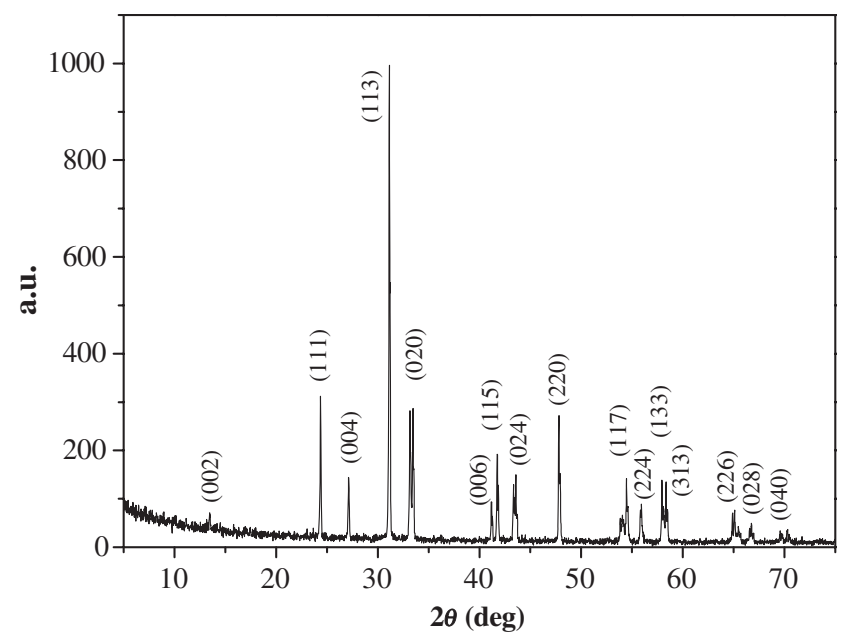

Figure 1. XRD pattern of $\mathrm{La}_{2} \mathrm{CuO}_{4}$ synthesized by nitrate route.

centre and one $\mathrm{CuO}_{3}$ layer removed. One of the cut cells is placed on the Cu-type cell of the perovskite structure. ${ }^{16}$ The average crystallite size $(D \sim 70 \mathrm{~nm})$ is calculated from the full-width at half-maximum $(\beta): D=0.94 \lambda\left(\beta \cos \theta_{h k l}\right)^{-1}$, where $\theta$ is the diffraction angle. Such size should give rise an active surface of $\sim 12 \mathrm{~m}^{2} \mathrm{~g}^{-1}(=6 / \rho D)^{-1}$, $\rho$ being the density.

The band gap is of great importance in photocatalysis ${ }^{17}$ and the diffuse reflectance is (figure 2a) used to determine the optical transitions using the Pankov relation: ${ }^{18}$

$$
(\alpha h v)^{m}=C\left(h v-E_{\mathrm{g}}\right) .
$$

The intercept of the linear plot $(\alpha h v)^{2}$ with the $h v$-axis yield an optical transition of $1.27 \mathrm{eV}$, directly allowed $(m=2$, figure $2 b$ ).

In the electrochemistry of semiconductors, the corrosion must be investigated owing to its negative aspect for the longterm applications and the lifetime of the electrode is crucial for the solar conversion. To this end, the oxide was stored in $\mathrm{KOH}$ medium during 1 month and no dissolution was observed. Indeed, the solution was acidified and the amount of dissolved copper was too small to be detected by atomic absorption. The intensity potential $J(V)$ curve of $\mathrm{La}_{2} \mathrm{CuO}_{4}$ is traced to elucidate the electrochemical behaviour. The electrochemical stability over a wide potential range is supported by the semilogarithmic plot. The small current in the dark $\left(<1 \mathrm{~mA} \mathrm{~cm}^{-2}\right)$ is due to thermal excitation across the activation energy and $\mathrm{La}_{2} \mathrm{CuO}_{4}$ behaves as a chemical diode. Further support of the electrons localization is brought by a small peak at $\sim-0.5 \mathrm{~V} ; \mathrm{La}_{2} \mathrm{CuO}_{4}$ can be electrochemically oxidized according to the reaction

$$
\mathrm{La}_{2} \mathrm{CuO}_{4}+\tau \mathrm{H}_{2} \mathrm{O} \rightarrow \mathrm{La}_{2} \mathrm{CuO}_{4+\sigma}+2 \tau \mathrm{e}^{-}+2 \tau \mathrm{OH}^{-},
$$

where $\tau$ stands for the amount of oxygen over stochiometry. This result is in agreement with the idea that oxygen intercalates in the crystal lattice, responsible of the superconductivity. ${ }^{11}$ 

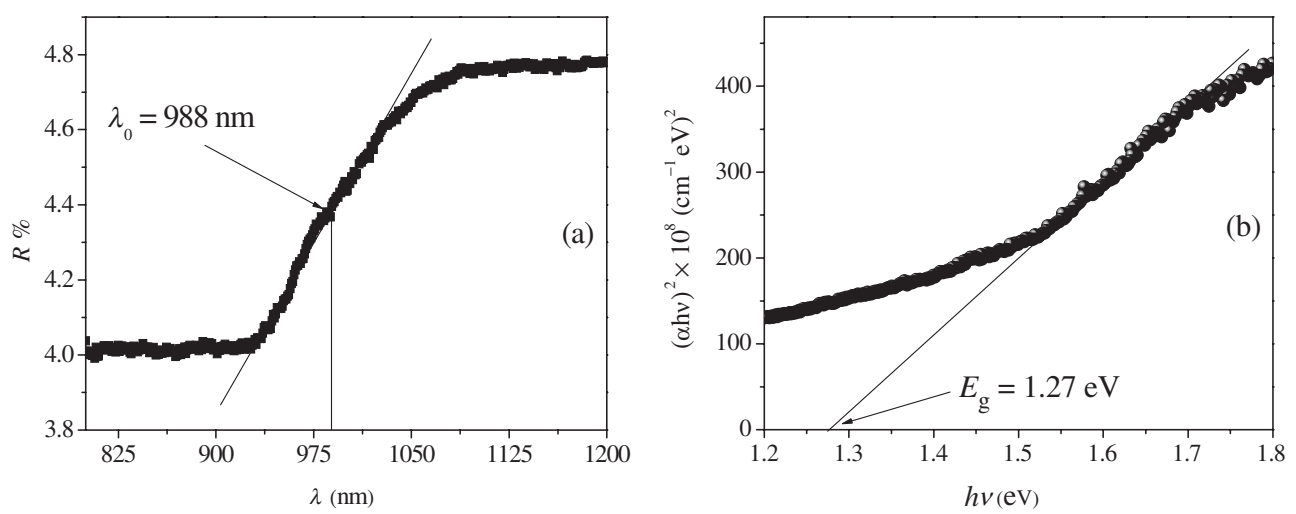

Figure 2. Diffuse reflectance spectrum of (a) $\mathrm{La}_{2} \mathrm{CuO}_{4}$ and (b) direct band gap transition.
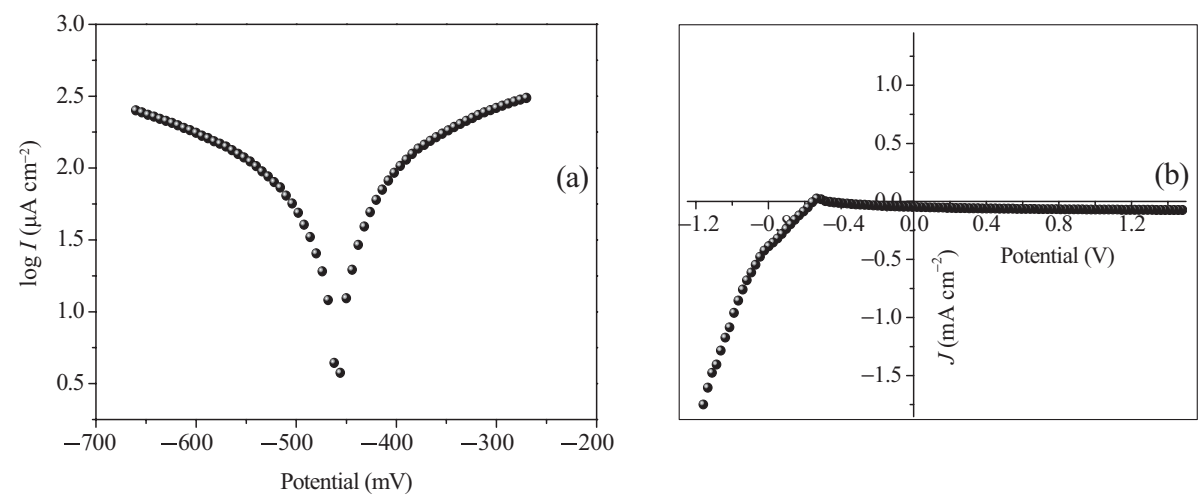

Figure 3. (a) Semi-logarithmic plot over $\mathrm{La}_{2} \mathrm{CuO}_{4}$ electrode in $\mathrm{KOH}$ electrolyte $(0.1 \mathrm{M}$, $\mathrm{pH} \sim 12.5$ ), scan rate: $5 \mathrm{mV} \mathrm{s}^{-1}$ and (b) intensity potential $J(V)$ characteristic.

A long lived electrode should have a small exchange current density current $J_{0}$; the current $J_{\mathrm{o}}$ is assimilated to the rate constant of the electron transfer at zero potential and a value of $61 \mu \mathrm{A} \mathrm{cm} \mathrm{cm}^{-2}$ is obtained (figure 3a). The point at which the $J_{\mathrm{d}}(V)$ curve intercepts the potential axis in the cathodic side corresponds to the hydrogen evolution reaction (HER) and a value of $-0.50 \mathrm{~V}$ is obtained. By contrast, no oxidation of water could be observed up to $1.5 \mathrm{~V}$. Hence, the water cannot be oxidized and a reducing agent is then required to react with the photoholes to improve the charge separation.

The photo-electrochemistry provides useful information on the solid state properties and is a suitable technique for drawing the energy band diagram, a preamble of the photocatalysis. The photocurrent $\left(J_{\mathrm{ph}}\right)$ is defined as the change in current induced under irradiation and to confirm the semiconducting like properties, figure $3 \mathrm{~b}$ shows the chronoamperometry under illumination (figure 4); the cathodic photocurrent $\left(J_{\mathrm{ph}}\right)$ is characteristic of p-type behaviour. The photocurrent decays rapidly, because the anodic bias is not large enough and such behaviour reflects an electron tunneling from $\mathrm{Cu}^{2+}: 3 \mathrm{~d}$ valence band to localized states. The position of the electronic bands is accurately determined from the capacitance measurement. The flat band potential $V_{\mathrm{fb}}(-0.41 \mathrm{~V})$ and the holes density $N_{\mathrm{A}}\left(1.75 \times 10^{19} \mathrm{~cm}^{-3}\right)$ are provided, respectively, from the intercept of the potential axis at

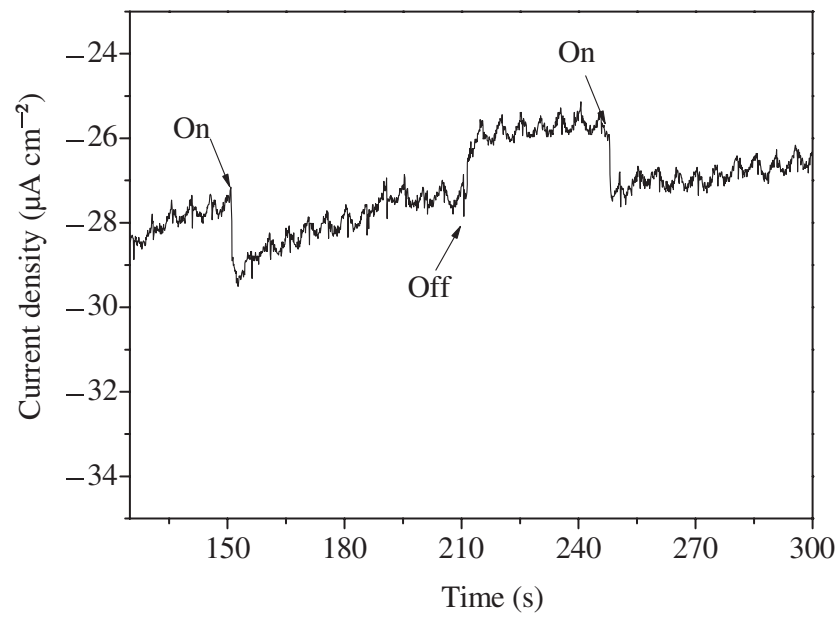

Figure 4. Time response of the short-circuit current of $\mathrm{La}_{2} \mathrm{CuO}_{4}$ under chopped light, indicating the p-type behaviour.

$C^{-2}=0$ and the slope of the straight line of the MottSchottky plot (figure 5):

$$
C^{-2}= \pm\left(2 / e \varepsilon \varepsilon_{0} N_{\mathrm{A}}\right)\left\{V-V_{\mathrm{fb}}-k T / e\right\},
$$

where $\varepsilon_{0}$ is the permittivity of vacuum $\left(8.85 \times 10^{-12}\right.$ $\left.\mathrm{F} \mathrm{m}^{-1}\right)$. The permittivity of $\mathrm{La}_{2} \mathrm{CuO}_{4}(\varepsilon=105)$ is obtained 


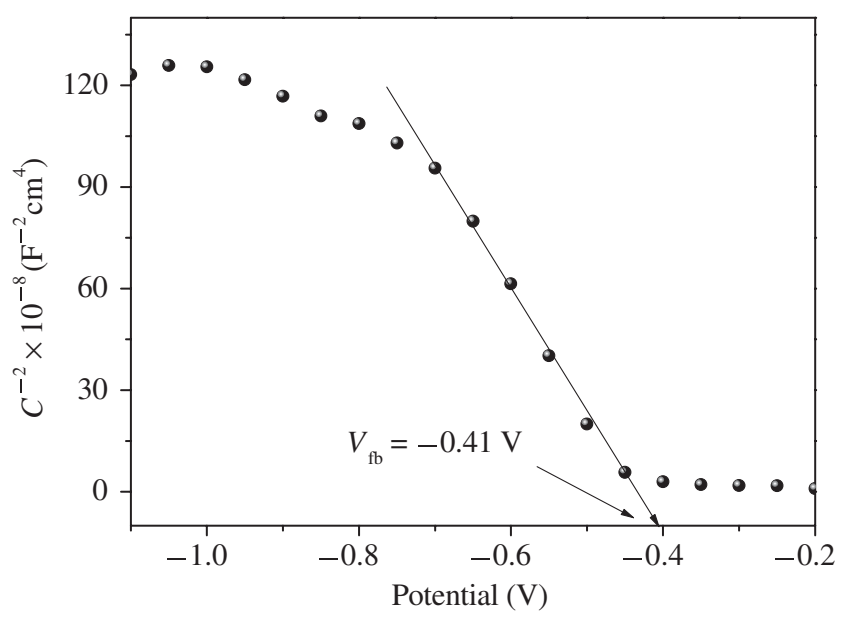

Figure 5. Mott-Schottky characteristic of $\mathrm{La}_{2} \mathrm{CuO}_{4}$ in $\mathrm{KOH}$ solution (0.1 M, pH 12.5) plotted at a frequency of $100 \mathrm{kHz}$.

from the literature ${ }^{8}$ and the corrective term $k T / e(\sim 26 \mathrm{mV})$ can be neglected. The negative slope confirms the p-type behaviour of $\mathrm{La}_{2} \mathrm{CuO}_{4}$ in conformity with mixed copper valences $\mathrm{Cu}^{3+/ 2+}$ and oxygen insertion, responsible of the superconductivity. ${ }^{19}$

The oxide exhibits a semiconducting behaviour and the hole mobility $\left(4.2 \times 10^{-3} \mathrm{~cm}^{2} \mathrm{~V}^{-1} \mathrm{~s}^{-1}\right)$, evaluated from the relation $\left(\sigma=\mathrm{e} \mu_{\mathrm{h}} N_{\mathrm{D}}\right)$, is inferred to the a wide valence band deriving from $\mathrm{O}^{2-}: 2 \mathrm{p}$ orbital. The energetic position of the conduction band with respect to vacuum is given by

$$
P=4.74+e V_{\mathrm{fb}}-E_{\mathrm{g}}+E_{\mathrm{a}}^{1}+0.059(\mathrm{pH}-\mathrm{pzc}),
$$

4.75 is the energy of the reference electrode (SCE) with respect to vacuum and $\mathrm{pzc}$ the $\mathrm{pH}$ for which the net adsorbed charge on the surface is zero, it has been evaluated at 6.42 . The linear plot $\left(C^{-2}-V\right)$ indicates a constant density, characteristic of a moderately doped semiconductor with an extended space-charge region: ${ }^{20}$

$$
\delta=\left\{2 \varepsilon \varepsilon_{\mathrm{o}}\left(V_{\mathrm{fb}}-\mathrm{V}\right) / e N_{\mathrm{A}}\right\}^{1 / 2} .
$$

The $\delta$-value $(18 \mathrm{~nm})$ agrees with the non-degenerate conductivity. Hence, the conduction band $(\sim-1.5 \mathrm{~V})$, deduced from the relation $\left(P-E_{\mathrm{g}}\right)$, is more cathodic than the hydrogen level $(-0.5 \mathrm{~V})$, leading to a spontaneous water reduction upon visible light. The $P$-value $(-0.41 \mathrm{~V} / 4.44 \mathrm{eV})$ indicates that the valence band is made up predominantly of $\mathrm{Cu}^{2+}: 3 \mathrm{~d}$ orbital.

The EIS plot of the junction $\mathrm{La}_{2} \mathrm{CuO}_{4} / \mathrm{KOH}$ solution plotted at the open circuit potential (OCP), shows one semicircle in the high-frequency range attributed to the intrinsic faradic charge transfer (bulk contribution). Accordingly, the impedance of the system is mainly determined by the depletion region and the large diameter indicates relatively a

\footnotetext{
${ }^{1}$ The average activation energy $\left(E_{\mathrm{a}} \sim 0.1 \mathrm{eV}\right)$ was measured from the conductivity measurements on sintered pellets.
}

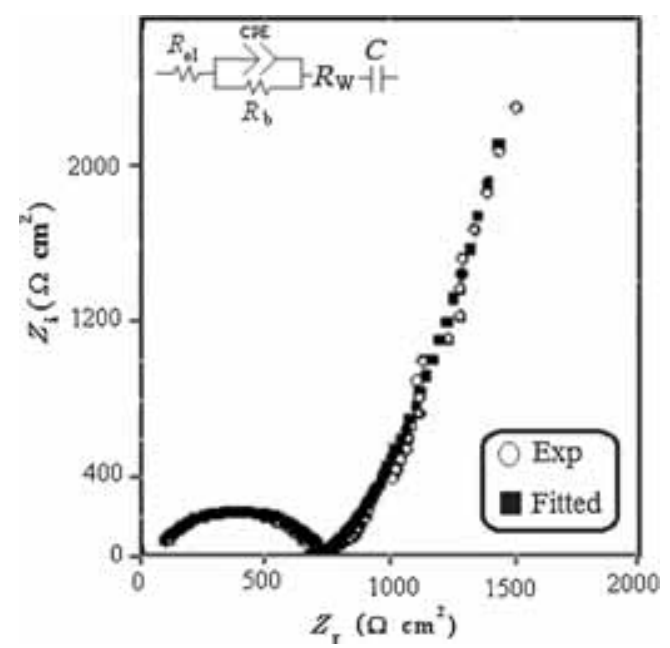

Figure 6. Impedance diagram of $\mathrm{La}_{2} \mathrm{CuO}_{4}$ in $\mathrm{KOH}$ electrolyte ( $\mathrm{pH} \sim 12.5$ ). The experimental and fitted plots.

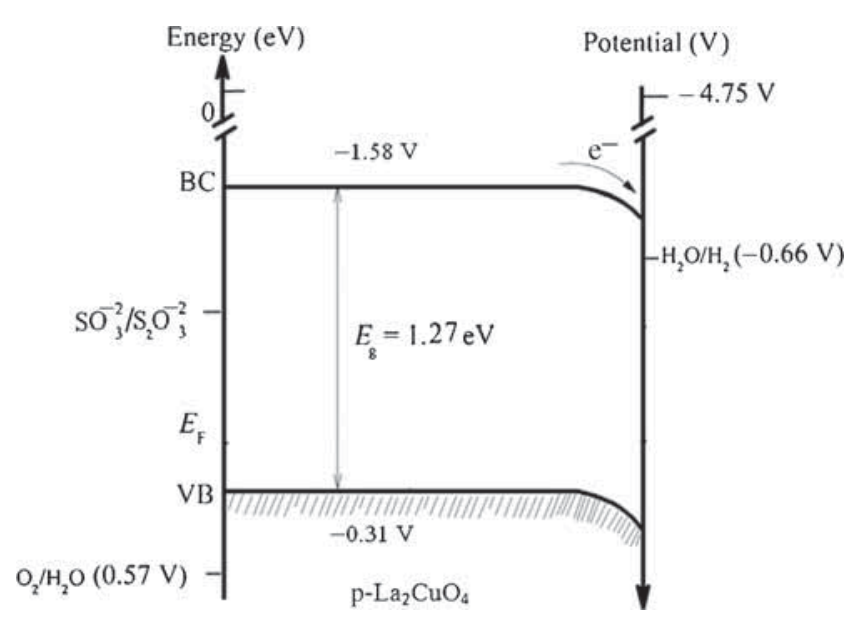

Figure 7. Energy-level diagram of p-Lan $\mathrm{CuO}_{4} / \mathrm{S}_{2} \mathrm{O}_{3}^{2-}$ /electrolyte junction.

moderate bulk resistance $R_{\mathrm{b}}\left(670 \Omega \mathrm{cm}^{2}\right)$; the centre is localized below the real axis with a depletion angle of $9^{\circ}$ suggesting that the electron hopping occurs by crossing a low potential barrier. To take into account the nonideal behaviour of the capacity, a constant phase element (CPE) is introduced:

$$
\mathrm{Z}=\{Q(j \omega) n\}^{-1},
$$

where $Q$ is a frequency-independent constant, $j$ the imaginary number $\left(j^{2}=-1\right)$ and $\omega$ the angular frequency. The substitution of the interfacial capacitance by $Q(\mathrm{i} \omega)^{-n}$ where $n$ the homogeneity factor $(0<n \leq 1)$ is related to the phase angle $\varphi(=n \pi / 2)$. The offset near the origin is due to the low resistance of the ionic electrolyte $\left(R_{\mathrm{el}}=56 \Omega \mathrm{cm}^{2}\right)$ attributed to the high mobility of $\mathrm{OH}^{-}$specie. ${ }^{19}$ The straight line at low frequencies region is due to Warburg diffusion $(W)$. The $n$-value $(=0.76)$ indicates a large deviation from the ideal capacitance. The EIS data are modelled to an equivalent electrical circuit (figure 6, inset) composed by CPE in 


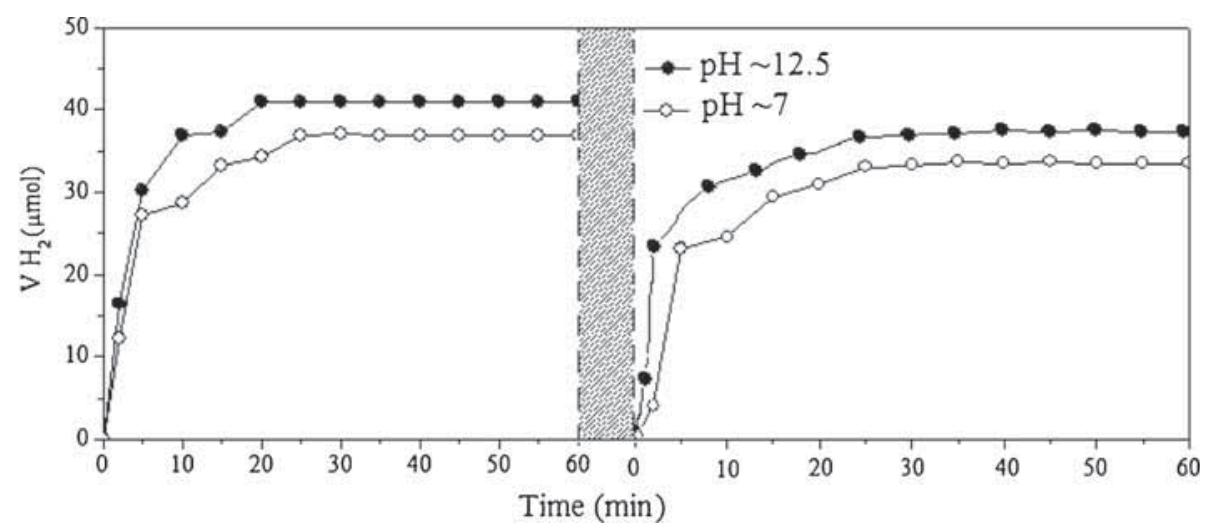

Figure 8. Time course evolution of hydrogen on the system $\mathrm{La}_{2} \mathrm{CuO}_{4} / \mathrm{SO}_{3}^{2-}(0.01 \mathrm{M})$ at $\mathrm{pH} \sim 12.5$ and $\mathrm{pH} \sim 7$.

parallel with the bulk resistance $\left(R_{\mathrm{b}}\right)$ and connected in series with the resistance $\left(R_{\mathrm{W}}\right)$ and the capacitance $(C=0.022 \mathrm{~F})$.

\subsection{Photocatalysis}

Relatively little work was done on the PEC characterization of $\mathrm{La}_{2} \mathrm{CuO}_{4}$ and no photocatalytic applications were reported much except the recent paper of water discharge under illumination. ${ }^{21} \mathrm{~A}$ cathodic flat band potential and absorption properties over the visible region are required for an efficient photocatalyst. In both respect, $\mathrm{La}_{2} \mathrm{CuO}_{4}$ seems to be an attractive material in addition to be safe and can be easily prepared by a chemical route. To understand how the electrode converts the light into chemical energy, we have drawn the energy diagram of the junction $\mathrm{La}_{2} \mathrm{CuO}_{4} / \mathrm{KOH}$ solution, established from the PEC characterization (figure 7). The diagram clearly shows the feasibility of $\mathrm{La}_{2} \mathrm{CuO}_{4}$ for the photochemical hydrogen liberation.

$\mathrm{La}_{2} \mathrm{CuO}_{4}$ excited by visible light provides electrons in the conduction band which are transferred to water. However the water photoelectrolysis into $\mathrm{O}_{2}$ and $\mathrm{H}_{2}$ requires a gap greater than $2.46 \mathrm{eV}$ molecule ${ }^{-1}$, taking into account the over-potentials. Hence, oxygen cannot be liberated because of the unfavourable position of $\mathrm{La}_{2} \mathrm{CuO}_{4}-\mathrm{VB}(\sim 1.3 \mathrm{~V})$. So, to preclude the photocorrosion of $\mathrm{La}_{2} \mathrm{CuO}_{4}, \mathrm{~S}_{2} \mathrm{O}_{3}^{2-}$ is added as reducing agent. With a potential of $\sim-0.3 \mathrm{~V}$, $\mathrm{S}_{2} \mathrm{O}_{3}^{2-}$ could scavenge the photoholes and the oxidation proceeds fast enough to maintain the holes concentration below the critical threshold required to prevent the photo corrosion. In addition, $\mathrm{S}_{2} \mathrm{O}_{3}^{2-}$ reduces considerably the lost of electron/hole $\left(\mathrm{e}^{-} / \mathrm{h}^{+}\right)$pairs, thus resulting in an efficient hydrogen evolution by increasing the lifetime of the charge carriers.

The two half electrochemical reactions occur concomitantly on the opposite poles of the $\mathrm{La}_{2} \mathrm{CuO}_{4}$ crystallite with behaves like a micro-PEC cell. The large resistance $R_{\mathrm{b}}$ appears to have a positive effect on that the width of the space charge region is large, allowing the contribution of most $\left(\mathrm{e}^{-} / \mathrm{h}^{+}\right)$pairs. The evolved volume increases monotonically over illumination time with an evolution rate of $20.6 \mu \mathrm{mol} \mathrm{min}-1$ (g catalyst) $^{-1}$ (figure 8 ). The conversion efficiency $(\eta)$ of light energy into hydrogen is given by

$$
\eta=\left\{2 \text { number of } \mathrm{H}_{2} \mathrm{~mol} / \text { number of effective photons }\right\}
$$

$\eta$-value of $0.22 \%$ is determined under full light. The rate decreases over time and beyond $20 \mathrm{~min}$, the photoactivity tends to zero, due to the saturation of actives sites by molecular hydrogen. This is evident from the fact that with the substitution of the solution by a new one or by purging with nitrogen, the initial performance of the catalyst is restored (figure 6), a desactivation of less than $5 \%$ is observed. The study is the subject of continuing interest on the homologous compound $\mathrm{La}_{2} \mathrm{NiO}_{4}$ and the results will be published in near future.

\section{Conclusion}

$\mathrm{La}_{2} \mathrm{CuO}_{4}$ has environmental-friendly characteristic and has been prepared by a chemical route. The chemical and electrochemical stabilities make it attractive for the solar energy conversion. It absorbs over the whole solar spectrum and exhibits an excellent chemical stability. It was characterized photo-electrochemically with p-type behaviour. The conduction band $(\mathrm{CB})$ is appropriately positioned with respect to the $\mathrm{H}_{2} \mathrm{O} / \mathrm{H}_{2}$ level and the oxide is successfully tested for the hydrogen production under visible light. The best performance occurs in alkaline medium and the oxide is stabilized in presence of $\mathrm{S}_{2} \mathrm{O}_{3}^{2-}$ as holes scavenger.

\section{References}

1. Stroyuk A L, Kryukov A I, Kuchmii S Y and Pokhodenko V D 2009 Theor. Exp. Chem. 45209

2. Cui W, Li L, Liangrong F, Xu C, Zijian L, Shaojie L and Fali Q 2006 Sci. China Ser. B 49162 
3. Koriche N, Bouguelia A and Trari M 2006 Int. J. Hydrogen Energy 311196

4. Raja K S, Mahajan V K and Misra M 2006 J. Power Sources 1591258

5. Goto S, Takashi U and Chouho Y 2001 Sol. Energy Mater. Sol. Cells 66631

6. Boumaza S, Bouarab R, Trari M and Bouguelia A 2002 Energy Convers. Manage. $\mathbf{5 0} 62$

7. Bak T J, Nowotny M, Rekas and Sorrell C 2002 Int. J. Hydrogen Energy 27991

8. Varyukhin S V and ZAkharov A A 1991 Physica C: Superconductivity 185975

9. Omeiri S, Allalou N, Rekhila G, Bessekhouad Y and Trari M 2013 Appl. Nanosci. 18

10. Tiwari S and Sanjay T 2006 Sol. Energy Mater. Sol. Cells 90 1621

11. Grenier J C, Wattiaux A, Lagueyte N, Park J C, Marquestaut E, Etourneau J and Pouchard M Physica C. Superconductivity 173139
12. Yifeng L, Jianfeng H, Liyun C, Jianpeng W and Jie F 2012 Mater. Charact. 6436

13. Zhang Z, Xiaohong C, Xianwen Z, Huaxiang L, Huan L, Yangen Z and Xuxu W 2013 Catal. Commun. 3620

14. Belevtsev B I, Dalakova N V and Panfilov A S 1997 Physica C 2821223

15. Van't S H, Dan S and Frans O 2008 Int. J. Hydrogen Energy 336414

16. Galasso F S 1970 Structure and properties of inorganic solids (Oxford: Pergamon) vol. 7

17. Chunhui Z, Jing G, Zhuangzhi L, Hongjuan $\mathrm{Z}$ and Guide $\mathrm{T}$ 2015 Physica B: Condens. Mater. 45626

18. Enhessari M, Shaterian M, Javad M E and Mohammad N 2013 Mater. Sci. Semicond. Proc. 1615

19. Radecka M, Rekas M, Trenczek A Z and Zakrzewska K 2008 J. Power Sources 18146

20. Khettab M, Omeiri S, Sellam D, Ladjouzi M A and Trari M 2012 Mater. Chem. Phys. 132625

21. Priya R and Kanmani S 2010 Bull. Mater. Sci. 3385 